\title{
CONFLITO ENTRE NOMES DE DOMÍNIO E MARCA
}

\author{
Daniel Evangelista Vasconcelos Almeida* \\ Juliana Evangelista de Almeida**
}

SUMÁRIO: Introdução; 2 Marcas; 3 Nomes de domínio - surgimento e evolução; 3.1 Estrutura do nome de domínio; 3.2 Registro e princípios norteadores; 4 Conflitos entre marca e nome de domínio; 4.1 Conflitos jurisdicionados? Casos submetidos à ICANN e ao CGI.br; 4.2 First served, first come ou priorização do direito marcário?; 5 Conclusão; Referências.

RESUMO: Conquanto se trate de um fenômeno relativamente recente, a internet é um marco na atividade empresarial, sendo que muitos empresários usam desta para o exercício da empresa. Na internet, o acesso aos sites é feito por meio dos Nomes de Domínio, razão pela qual este é relevante no mercado, tendo em vista que irá identificar a atividade na rede mundial de computadores. Do mesmo modo, a marca, espécie de propriedade industrial, identifica o produto ou o serviço prestado, razão pela qual merece proteção. Ressalta-se que o registro das marcas e dos nomes de domínio, além de não seguir as mesmas regras, é de competência de órgãos distintos. Neste ínterim, o artigo tem como problema de pesquisa a investigação da possibilidade de existência da prática de concorrência desleal e/ou concorrência parasitária quando existir conflito entre o uso de um domínio e o uso de uma marca já registrada. Tem-se por objetivo abordar o conflito, evidenciando as nuances atinente à matéria, analisando principalmente os institutos das marcas e dos nomes de domínio, bem como dos institutos da concorrência desleal e parasitária. Utilizará o método dedutivo explanatório por meio de pesquisa bibliográfica e análise de casos.

PALAVRAS-CHAVE: Propriedade intelectual; Propriedade industrial; Marca; Nome de domínio; Internet.

\section{CONFLICT BET WEEN TRADEMARKS AND DOMAIN NAMES}

ABSTRACT: Although it is a relatively recent phenomenon, the Internet is a boundary in business activity, and many entrepreneurs use this to pursue the company. On the Internet, the access to sites is done by the Domain Name, which is the reason why this is relevant in market, considering that will identify the activity

\footnotetext{
Mestre em Direito Privado pela PUC Minas. Especialista em Direito Civil e Processual Civil, pela FEAD. Advogado em Direito Digital, Brasil. Email danielevangelista@gmail.com

** Doutora em Direito Privado pela PUC Minas. Professora da FACHI-Funcesi e da Nova Faculdade. Advogada em Direito Digital, Brasil.
} 
on the world wide web. In the same way, the trademark, kind of industrial property, identifies the product or service, which is the reason that it deserves protection. The registration of trademark and domain names, moreover of do not follow the same rules, it is done by different organs. Thus, the article has as a research problem the investigation of the existence of the practice of unfair competition and/or parasitic competition when there is a conflict between the use of a domain and the use of an already registered trademark. The objective is to approach the conflict, highlighting the points regarding the matter, analyzing mainly the institutes of the Marks and Domain Names, as well as institutes of unfair and parasitic competition. It will be used the explanatory deductive method through bibliographic research and case analysis.

KEY WORDS: Intellectual Property; Industrial property; Trademark; Domain name; Internet.

\section{CONFLICTO ENTRE NOMBRES DE DOMINIO Y MARCA}

RESUMEN: Aunque se trate de un fenómeno relativamente reciente, la Internet es un hito en la actividad empresarial, pues muchos empresarios la utilizan para el ejercicio de la empresa. En la Internet, el acceso a los sitios lo hacen por intermedio de los Nombres de Dominio, razón por la cual este es relevante en el mercado, teniendo en cuenta que identificará la actividad en la red mundial de computadores. De igual modo, la marca, especie de propiedad industrial, identifica el producto o el servicio ofrecido, razón por la cual merece protección. Se resalta que el registro de las Marcas y de los nombres de Dominio, además de no seguir las mismas reglas, es de competencia de órganos distintos. Mientras tanto, el artículo tiene como problema de pesquisa la investigación de la posibilidad de existencia de la práctica de competencia desleal y/o competencia parasitaria cuando haya conflicto entre el uso de un dominio y el uso de una marca ya registrada. Se tiene por objetivo abordar el conflicto, evidenciando los matices atinentes a la materia, analizándose principalmente los institutos de las Marcas y de los Nombres de Dominio, así como de los institutos de la competencia desleal y parasitaria. Se utilizará el método deductivo explicativo por intermedio de investigación bibliográfica y análisis de casos.

PALABRAS CLAVE: Propiedad Intelectual; Propiedad Industrial; Marca; Nombre de Dominio; Internet. 


\section{INTRODUÇÃO}

A internet é hoje uma realidade na sociedade, sendo certo que após o seu advento muitas foram as alterações no modo de se viver desta. Assim, muitas são as práticas que se inserem em meio digital, dentre as quais se destacam as atividades empresárias.

No entanto, não há uma legislação extensa sobre o assunto, posto que se trata de um fenômeno relativamente recente. Assim sendo, muitos são os conflitos que podem ocorrer na rede mundial de computadores.

Nesse diapasão, com base nos Princípios Constitucionais da livre iniciativa e da livre concorrência, o sistema de proteção do Direito Marcário e considerando que o avanço da internet culminou na era da informação com reflexos inclusive no Direito Empresarial, o presente trabalho discute o conflito entre nomes de domínio e marca.

Brevemente, para se acessar uma informação em um site, é preciso se conectar a este por meio de um nome de domínio. O nome de domínio é um facilitador, já que sem ele, seria necessário memorizar uma série de códigos.

Atinente às marcas, a proteção é inserida inclusive no rol de direitos fundamentais, conforme incisos XXVII e XXIX do artigo $5^{\circ}$ da Constituição da República de 1988.

Observe que existem alguns requisitos para que se tenha o registro de uma marca, entre eles se destacam os princípios da inovação e da especialidade. Conforme as diretrizes do próprio INPI - Instituto Nacional da Propriedade Intelectual, o primeiro versa que a marca deve ser nova, sendo vedada a reprodução de outra anteriormente registrada. O segundo consiste em se ter proteção somente em um dado segmento ou setor. Assim é que podem coexistir duas marcas idênticas no mesmo período de tempo, sendo ambas protegidas pelo ordenamento jurídico e sem estar-se diante de um conflito.

Por sua vez, o registro de um domínio segue apenas o princípio do first server, first come, ou seja, a proteção e consequente titularidade será conferida àquele que primeiro requerer o registro no órgão competente, privilegiando o ineditismo.

As marcas e os nomes de domínio são institutos distintos, sendo que, inclusive o registro é de atribuição diversa. As marcas, no Brasil, são registradas 
junto ao INPI, enquanto que o nome de domínio é registrado no Comitê Gestor da Internet no Brasil - CGI.br ou Internet Corporation for Assigned Names and Number - ICANN, a depender da estrutura a ser utilizada.

Desta feita, é possível que uma pessoa registre um domínio que reproduza uma marca sem ser o titular desta. Estar-se-ia diante de um conflito? Ora, de um lado temos um regime próprio de proteção às marcas e de outro o sistema dos nomes de domínio. Há que se investigar as possíveis soluções jurídicas dessa situação.

O nome de domínio é um facilitador entre o usuário e o site, posto que sem ele o acesso à informação se daria com a utilização de códigos numéricos de difícil memorização. Portanto, assim como a marca, o nome do estabelecimento, o nome empresarial e outros sinais distintivos, o nome de domínio tem uma função importante na atividade empresária, sendo certo que goza de proteção.

O objetivo do presente trabalho é compreender como se dá a proteção aos nomes de domínio e às marcas, para se verificar o possível conflito entre estes. Para tal, o capítulo 2 aborda a conceituação de marca. No capítulo 3, será explanado o surgimento e a evolução dos nomes de domínio. Por fim, o capítulo 4 trabalha a ideia do conflito entre marca e nome de domínio.

\section{MARCAS}

Sobre marcas, Denis Barbosa leciona que

[...] marca é o sinal visualmente representado, que é configurado para o fim específico de distinguir a origem dos produtos e serviço. Símbolo voltado a um fim, sua existência fática depende da existência destes dois requisitos: capacidade de simbolizar, e capacidade de indicar uma origem específica, sem confundir o destinatário do processo de comunicação em que se insere: o consumidor. Sua proteção jurídica depende de um fator a mais: a apropriabilidade, ou seja, a possibilidade de se tornar um símbolo exclusivo, ou legalmente unívoco, em face do objeto simbolizado ${ }^{03}$

Marca é, pois, um sinal distintivo da atividade empresária que compõe a propriedade industrial identificando um produto ou serviço, distinguindo-o

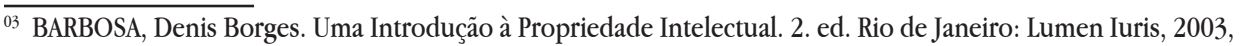
p. 803. 
no mercado de outro produto ou serviço de origem distinta. Assim, se diz que o consumidor associa a marca à qualidade do produto ou serviço.

Neste diapasão, têm-se duas funções das marcas, quais sejam, as funções essenciais e as funções secundárias. Entende-se por função essencial da marca a distinção que ela atribui ao bem ou serviço, distinguido-o no mercado, sendo esta a função mais relevante. Destarte, tem-se a função secundária da marca, pois esta serve como uma indicação de origem, qualidade, econômica e publicitária.

Segundo Barros $^{04}$, o direito de marcas é regido pelos princípios da distinguibilidade, veracidade, novidade, disponibilidade, especialidade e territorialidade. Por sua vez, Coelho ${ }^{05}$ não trata a matéria como princípios, mas como condições, sendo estas a da novidade relativa, não colidência com notoriamente conhecida e desimpedimento.

Princípio que merece atenção é o da especialidade. Sobre o tema, leciona Fabio Ulhoa Coelho ${ }^{06}$ que "pelo 'princípio da especificidade', a proteção da marca registrada é limitada aos produtos e serviços a respeito dos quais podem os consumidores se confundir $[\ldots]^{107}$. Segundo tal princípio, será protegida a marca apenas para um determinado ramo, o que permite a existência simultânea de duas ou mais iguais, desde que para atividades distintas ${ }^{08}$.

O que se quer dizer é que a marca é registrada apenas para um ramo da atividade empresarial, sendo possível a coexistência pacífica entre duas ou mais iguais, desde que para atividades distintas. Assim, o INPI, órgão responsável para o registro das marcas, dispõe de uma lista com 45 classes $^{09}$, dentre as quais se distinguem a atividade do empresário.

Entretanto, há uma exceção na qual não se pode utilizar um sinal distintivo em outra especialidade, qual seja, a marca de alto renome. "Nesta hipótese, a

${ }^{04}$ BARROS, Carla Eugenia. Manual da Propriedade Intelectual. Aracaju: Evocati, 2007.

${ }^{05}$ COELHO, Fábio Ulhoa. Manual de Direito Comercial: direito de empresa. 23. ed. São Paulo: Saraiva, 2011.

${ }^{06}$ Fábio Ulhoa Coelho (2011) utiliza a nomenclatura de "princípio da especificidade" e não "princípio da especialidade" como neste trabalho optou por utilizar, contudo, não há diferença no conceito, mas tão somente um estilo linguístico distinto.

${ }^{07}$ COELHO, Fábio Ulhoa. Manual de Direito Comercial: direito de empresa. 23. ed. São Paulo: Saraiva, 2011, p. 177.

${ }^{08}$ CORRÊA, Júlio César Dutra. Nome de domínio: Enseja proteção equiparável às marcas ou é apenas mais um signo distintivo para o exercício da atividade empresarial?. Âmbito Jurídico, Rio Grande, XV, n. 96, jan 2012. Disponível em: < http://www.ambito-juridico.com.br/site/?n_link=revista_artigos_leitura\&artigo_ $\mathrm{id}=11054$ \&revista_caderno $=8>$. Acesso em: set 2014 .

${ }^{09}$ A lista pode ser acessada através do link < http://www.inpi.gov.br/images/docs/ncl\%2810\%29_-_2015_guia_ do_usuario_e_notas_explicativas_retificado_em_pdf.pdf > 
proteção é ampliada para todos os ramos da atividade econômica." ${ }^{10}$. A marca de alto renome é única, não comportando outras de igual distinção em qualquer ramo de atuação.

Salienta-se que para a proteção da marca é necessário o registro no órgão competente, qual seja, o INPI. O que se quer dizer é que mesmo que uma marca preencha todos os princípios, a mesma não terá proteção até o requerimento de registro junto ao INPI a não ser que se trate de marca notoriamente reconhecida, pois apenas esta precede de registro.

\section{NOMES DE DOMÍNIO - SURGIMENTO E EVOLUÇÃO}

A internet é hoje uma realidade, a qual revolucionou e revoluciona a forma como a sociedade vive. Observe que hoje é muito comum as empresas venderem produtos através da rede mundial de computadores, o que aumenta o alcance destas no mercado. Tamanha a importância da internet que já foi, inclusive, considerada bem indispensável à vida ${ }^{11}$. É possível, pois, afirmar que atualmente a atividade empresarial vive uma nova Era, a qual se denomina de era digital ou até mesmo sociedade da informação ou sociedade em rede.

$\mathrm{Na}$ atualidade, o acesso à informação é muito simples. Graças à internet um usuário consegue realizar diversas tarefas na rede, sem se deslocar, o que antes do advento desta seria inimaginável. Há diversas formas para a comunicação entre os computadores. Mas, usualmente, o acesso na internet ocorre por meio do Protocolo Internet, o que se conhece por IP.

Tudo que está conectado à rede mundial de computadores possui um número de IP, uma sequência de números composta por 32 bits. "O número 172.31.110.10 é um exemplo. Repare que cada octeto é formado por, no máximo três caracteres, sendo que cada um pode ir de 0 a 255 . Verifica-se cada octeto separado por um ponto."12. Dessa forma, todos os dispositivos que acessam a internet como, por exemplo, computadores, celulares e tablets, possuem um número IP único. É como se o IP fosse a identidade do dispositivo na rede, o que não admite imitação.

\footnotetext{
${ }^{10}$ COELHO, Fábio Ulhoa. Manual de Direito Comercial: direito de empresa. 23. ed. São Paulo: Saraiva, 2011, p. 177.

${ }^{11}$ CORTE ALEMÃ julga internet como serviço essencial. Mundo Positivo. 25 jan. 2013. Disponível em: < http:// www.mundopositivo.com.br/noticias/brasil/20138626-corte_alema_julga_internet_como_servico_essencial. html> Acesso em: 25 jan. 2015.

${ }^{12}$ BRANT, Cássio Augusto Barros. Marco Civil da Internet: comentários sobre a Lei 12.965/2014. Belo Horizonte: Editora D’Plácido, 2014, p. 140.
} 
No mesmo sentido, todo o conteúdo da rede possui um número IP, inclusive os websites.

Destarte, é muito complexa a memorização de uma sequência de números, ao passo que nomes se guardam com maior facilidade. Assim, visando facilitar o acesso de informações na rede é que o Sistema de Domínio, o Domain Name System (DNS), propicia a substituição do endereço numérico pela utilização de um nome.

O DNS substitui um endereço de um site por uma sequência de IP, ou seja, utiliza um conjunto de palavras ao invés de uma sequência numérica. Assim, ao se digitar em um navegador o endereço "www.receita.gov.br" o DNS irá transformar esse endereço naquela sequência numérica que corresponde ao IP do respectivo site. Observe que a memorização de um domínio é mais simples que a de um endereço IP. Dessa maneira, todo o site, além do servidor que hospeda o conteúdo, possui também um servidor DNS. Assim sendo, o acesso a conteúdos na internet é feito por meio dos nomes de domínio.

No âmbito empresarial, um site pode hospedar não somente um conteúdo a respeito do produto ou serviço oferecido pela empresa, mas também ser este. É o caso, por exemplo, dos e-commerce (comércio eletrônico). Vive-se um aumento exponencial destes, que consistem em sites que vendem produtos diretamente da rede mundial de computadores. Ou seja, a atividade empresarial é desenvolvida na internet, razão pela qual há discussão na doutrina moderna a respeito do que se denomina estabelecimento virtual ${ }^{13}$.

Neste diapasão, a internet revolucionou não só o meio de acesso à informação, mas também o direito empresarial como um todo. Assim, se faz necessária a análise deste fenômeno para a melhor compreensão das atividades empresariais nos dias atuais.

\subsection{ESTRUTURA DO NOME DE DOMÍNIO}

Os nomes de domínio identificam os sites, sendo que estes devem respeitar uma forma pré-ordenada para a apresentação ao usuário. Em âmbito originário ${ }^{14}$, ou como afirma Côrrea (2014), em âmbito mundial, os domínios são registrados

\footnotetext{
13 GUIMARÃES, Ana Caroline Faria; NEVES, Rubia Carneiro. El establecimiento virtual y su condición de establecimiento empresarial secundario (Filial). Panorama of Brazilian Law, v. 2, $\mathrm{n}^{\circ}$ 2, 2014. Disponível em $<$ http://www.panoramaofbrazilianlaw.com/index.php/BrLaw/article/view/30>. Acesso em: 04 maio 2015.

${ }^{14}$ Se diz originário, pois a internet surgiu nos Estados Unidos, razão pela qual eles detêm originariamente o controle sobre esta.
} 


\section{e regulamentados pela ICANN - Internet Corporation for Assigned Names and} Number ${ }^{15}$. Já no Brasil, tal gerenciamento ocorre por conta do Comitê Gestor da Internet no Brasil - CGI.br ${ }^{16}$. O CGI.br, por meio de uma portaria, delegou ao NIC. br - Núcleo de Informação e Coordenação do ponto BR, tal controle, que por sua vez, delegou a um de seus órgãos, o Registro.br, tal atribuição.

Ressalta-se que o órgão Registro.br é quem tem função direta de registro e manutenção dos nomes de domínio no Brasil ${ }^{17}$. O Registro.br utiliza-se de normas para tal função, estabelecidas em 2008 por meio da resolução $008^{18}$.

De uma maneira geral, todos os nomes de domínio se constituem de elementos básicos, quais sejam, o "www", o domínio de segundo nível, o domínio de primeiro nível e o top level, sendo que a composição de um site se apresenta dessa forma.

Como exemplo, utilizar-se-á o site da Receita Federal, "www.receita.gov. br". O nome "receita" corresponde ao domínio de segundo nível, por sua vez o "gov" corresponde ao domínio de primeiro nível e o top level é o "br". Todos os países internamente possuem o seu próprio top level, exceto os Estados Unidos, que utilizam o domínio de primeiro nível "com" para designar seus sites. Cássio Brant ilustra bem a estrutura de um nome de domínio:

Como exemplo de nome de domínio, cita-se o endereço eletrônico que acessa a página do Tribunal de Justiça de Minas Gerais (TJMG). O nome de domínio no Brasil é constituído de alguns elementos que são exemplificados no endereço do TJMG: www.tjmg.jus.br. O endereço "www' é a World Wide Web, que corresponde à rede mundial de computadores. O 'tjmg' seria o domínio de segundo nível, que identifica a pessoa. A denominação 'jus' corresponde ao domínio de primeiro nível, que identifica a destinação da entidade, no caso, o poder judiciário. A designação "br" corresponde

\footnotetext{
${ }_{15}$ Disponível em http://www.icann.org/en/about

${ }^{16}$ O CGI.br foi criado pela portaria interministerial $n^{0} 147$, de 31 de maio de 1995, dos Ministérios da Comunicação e da Ciência e Tecnologia, e alterada pelo decreto presidencial $\mathrm{n}^{\circ} 4.829$, de 03 de setembro de 2003, para coordenar e integrar todas as iniciativas de serviços internet no país, sendo composto por membros do governo, do setor empresarial,do terceiro setor e da comunidade acadêmica. Disponível em http://www. cgi.br/sobre-cg/index.htm.

${ }^{17}$ CORRÊA, Júlio César Dutra. Nome de domínio: Enseja proteção equiparável às marcas ou é apenas mais um signo distintivo para o exercício da atividade empresarial?. In: Âmbito Jurídico, Rio Grande, XV, n. 96, jan 2012. Disponível em: < http://www.ambito-juridico.com.br/site/?n_link=revista_artigos_leitura\&artigo_ id $=11054 \&$ revista_caderno $=8>$. Acesso em set 2014 .

18 CGI.BR - Comitề Gestor da Internet no Brasil. Resolução CGI.br/RES/2008/008/P. Dispõe sobre os procedimentos para registro de nomes de domínio. Disponível em: http://www.cgi.br/resolucoes/ documento/2008/008. Acesso em: 17/09/2014.
} 
ao top level que identifica o país. Os Estados Unidos são os únicos que não têm denominação do país porque foram os idealizadores da Internet. Os de segundo nível é que causam problemas judiciais em relação aos nome de marcas. ${ }^{19}$

O domínio de segundo nível é que irá identificar o site, é como os usuários irão acessá-los, razão pela qual, pode gerar conflitos com outros nomes, como marcas, título de estabelecimento e nome empresarial, por exemplo. O usuário tem liberdade de escolha deste nome, bastando que respeite algumas regras que se verão a seguir.

O domínio de primeiro nível identifica ou tenta identificar a atividade desenvolvida pelo site. Diz-se tenta, pois o costume leva a sociedade a pensar que todo site brasileiro tem a composição ".com.br". Na realidade, o domínio de primeiro nível pode se apresentar de diversas formas como, por exemplo, "adv" para serviços advocatícios, dentre outros, conforme artigo 14 da resolução 008 (CGI. br, 2014) ${ }^{20}$. Ocorre que esta tentativa é falha, pois ao se idealizar um site, é comum pensar na existência apenas do "com", ignorando as demais. Ressalta-se que os sites registrados junto a ICANN terão apenas os domínios de primeiro e segundo nível, tendo em vista que os Estados Unidos não utilizam o top level.

O domínio de topo, ou simplesmente top level identifica o país de origem do site. Cada nação possui o seu e não se repete. A título exemplificativo, o Brasil utiliza "br" enquanto que o Canadá utiliza "ca".

É evidente o avanço que o nome de domínio trouxe para as atividades empresariais. Pode-se afirmar que nos dias atuais a empresa passa por uma nova Era, a era digital. Observe que ao se procurar um serviço ou produto muitos consumidores utilizam a internet, daí resultando a importância do nome de domínio. Neste sentido, a sua escolha e o correto uso podem ser essenciais para o sucesso de uma empresa.

\subsection{REGISTRO E PRINCÍPIOS NORTEADORES}

Ao contrário das marcas, o registro do nome de domínio é algo simplificado. Há apenas um princípio norteador, qual seja, o first served first come. Segundo este

\footnotetext{
${ }_{19}$ BRANT, Cássio Augusto Barros. Usucapião do direito de uso da propriedade intelectual. Disponível em: $<$ http://www.biblioteca.pucminas.br/teses/Direito_BrantCA_1.pdf > . Acesso em 05 maio 2015, p. 122.

${ }^{20}$ CGI.BR - Comitê Gestor da Internet no Brasil. Resolução CGI.br/RES/2008/008/P. Dispõe sobre os procedimentos para registro de nomes de domínio. Disponível em: <http://www.cgi.br/resolucoes/ documento/2008/008 > . Acesso em: 17 set. 2014.
} 
princípio, aquele que primeiro requerer o registro será o titular do domínio. Isso em conformidade com o artigo $1^{\circ}$ da resolução $008 .{ }^{21}$

Ocorre que o princípio do first served first come não é uma máxima. Há certas limitações. O que se quer dizer é que não são todos os vocábulos que são registráveis, as palavras de baixo calão ou abusivas, por exemplo, não são registráveis, conforme o parágrafo único do referido dispositivo normativo.

Como visto, há diversas opções de domínio de primeiro nível. Caso se requeira a designação "adv", por exemplo, é preciso que o usuário comprove a legitimação para tal, ou seja, comprove que seja advogado. O mesmo se refere para todos os demais domínios de primeiro nível, exceto os que utilizem "com" ou "net", tendo em vista que não há qualquer requisito para este conforme artigo 14, inciso VI, da resolução $008 .^{22}$

Portanto, o registro de um nome de domínio é algo simples, bastando que o usuário o requeira primeiro, cumprindo as exigências formais vistas. As exigências acima são para o registro de domínio no Brasil, sendo que cada país pode fazer suas exigências. Entretanto, de uma maneira geral, todos utilizam o princípio do first served, first come. ${ }^{23}$

\section{CONFLITOS ENTRE MARCA E NOME DE DOMÍNIO}

Tem-se que às marcas se aplica o princípio da especialidade, ou seja, será protegida apenas no ramo da atividade empresarial que se requereu, salvo nos casos de marca de alto renome. Assim sendo, existe a possibilidade de duas ou mais marcas idênticas serem registradas no INPI, sem que isso caracterize um conflito entre elas. No Brasil existe um exemplo claro, qual seja, a marca "Globo", que é utilizada pela empresa de telecomunicação, por outra empresa de produtos de limpeza e por outra que explora alimentos. Nesse caso, todas as três marcas existem ao mesmo

\footnotetext{
${ }_{21}$ CGI.BR - Comitê Gestor da Internet no Brasil. Resolução CGI.br/RES/2008/008/P. Dispõe sobre os procedimentos para registro de nomes de domínio. Disponível em: <http://www.cgi.br/resolucoes/ documento/2008/008 > . Acesso em: 17 set. 2014.

22 CGI.BR - Comitê Gestor da Internet no Brasil. Resolução CGI.br/RES/2008/008/P. Dispõe sobre os procedimentos para registro de nomes de domínio. Disponível em: http://www.cgi.br/resolucoes/ documento/2008/008. Acesso em: 17/09/2014.

${ }^{23}$ CORRÊA, Júlio César Dutra. Nome de domínio: Enseja proteção equiparável às marcas ou é apenas mais um signo distintivo para o exercício da atividade empresarial?. Âmbito Jurídico, Rio Grande, XV, n. 96, jan 2012. Disponível em: < http://www.ambito-juridico.com.br/site/?n_link=revista_artigos_leitura\&artigo_ $\mathrm{id}=11054 \&$ revista_caderno $=8>$. Acesso em: set 2014 .
} 
tempo e, segundo a atual normatização da LPI, podem coexistir sem a caracterização de conflito, pois pertencem a ramos empresariais distintos.

Ao contrário das marcas, o nome de domínio é único, não sendo possível a existência de dois idênticos. Nesse sentido, há que se ventilar o conflito que existe entre o nome de domínio e a marca. No exemplo supracitado, caso as três empresas requerem-se para si a titularidade do domínio "www.globo.com.br" para quem deve ser atribuída a titularidade? Pode-se afirmar que deve ser dado a quem primeiro requereu, pois ao nome de domínio se aplica o princípio do first served, first come, o que é questionável, conforme se verá a seguir.

Nesse aspecto, vale ressaltar que, conquanto exista a individualização da atividade empresária pelo domínio primário, "[...] o público em geral espera que os endereços Web sejam nomes curtos “emoldurados" pelo 'www.' e '.com'”. ${ }^{24}$ Assim sendo, é ineficaz a tentativa de aplicação do princípio da especialidade ao nome de domínio, visto que o mercado consumidor acredita que o domínio da marca "exemplo", é "www.exemplo.com" ou "www.exemplo.com.br", sendo que a grande maioria negligencia ou desconhece a existência de outros domínios primários.

Outro conflito existente decorre do fato de que, como já afirmado, para se registrar um nome de domínio, basta que se requeira, sendo que não é exigido prova de titularidade do nome a ser registrado. Assim sendo, caso se requeira um registro de certo nome de domínio cuja designação seja uma marca de outrem, regularmente registrada, estar-se-ia diante de um conflito.

Nesse aspecto, conforme Kaminski ${ }^{25}$, não se pode exigir que o titular da marca ao mesmo tempo requeira o registro do domínio, embora seja aconselhável. Do mesmo modo, a marca não pode ser um critério isolado, sob pena de o detentor desta conseguir obstar todo e qualquer registro que a contenha, seja qual for o domínio de primeiro nível o que "[...] não nos parece justo e coerente aos princípios da Internet." 26

Buscando uma solução para esses conflitos, Kaminski, sugere uma integração dos bancos de dados dos nomes de domínio e das marcas.

\footnotetext{
${ }^{24}$ KAMINSKI, Omar. Conflitos sobre nomes de domínio: a experiência com o Judiciário brasileiro. In: LEMOS, Ronaldo. WAISBERG, Ivo. Conflitos Sobre Nomes de Domínio e Outras Questões Jurídicas da Internet, São Paulo: Revista dos Tribunais, 2003. p. 248

25 Idem.

${ }^{26}$ Ibidem, p. 252.
} 
Quando do registro, diante da inviabilidade prática de análise criteriosa caso a caso no caso de domínios, uma alternativa poderia ser a integração do banco de dados de registro de domínios (Registro.br) com o de marcas (Inpi). Mas o empecilho mais evidente é a existência de diversas classes para o registro de marcas, e que as condições para o registro de marcas são muito mais austeras e solenes (v. art. 124 e seus incisos da Lei 9.279/96). ${ }^{27}$

Como se vê, é uma solução falha, pois não aborda a possibilidade de duas marcas idênticas, mas de classes distintas, requererem o uso de um mesmo domínio. Caso o registro de um domínio seja a junção de duas marcas, estar-se-ia diante de um uso indevido? É possível o registro de marca associada a nome pejorativo? No bojo dessas situações possíveis, têm-se alguns aspectos relevantes para a análise no caso concreto:

- notoriedade do nome ou da marca: conhecimento do público (projeção, tradição, relevância social";

- data de registro da empresa no Brasil (nome comercial e razão social);

- ramo de atividade;

- data do registro do domínio no Registro.br (anterior ou posterior à Resolução 1/98 CG/Br);

- data da concessão do registro (a data do depósito é mera expectativa de direito) da marca no INPI;

- existência de conteúdo associado ao domínio (relevância do contexto, boa-fé/propaganda enganosa, "pirataria");

- inexistência de conteúdo, ou ocorrência de redirecionamento de DNS (desvio de clientela: concorrência desleal);

- registro anterior de outros domínios contendo marcas notórias de terceiros, sob o mesmo CNPJ ou pelo mesmo responsável, com a intenção de auferir lucros ("cibergrilagem") ${ }^{28}$

Não é uma solução fácil, pois se trata claramente de conflito entre princípios. De um lado o princípio da territorialidade, o qual atribui proteção à marca em todo

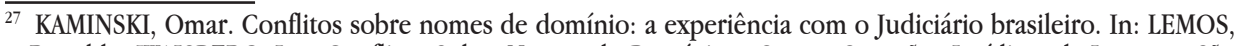
Ronaldo. WAISBERG, Ivo. Conflitos Sobre Nomes de Domínio e Outras Questões Jurídicas da Internet, São Paulo: Revista dos Tribunais, 2003. p. 251-252.

${ }^{28}$ Ibidem. p. 252. 
o território nacional, podendo inclusive ultrapassá-lo como visto, e de outro lado o princípio do first served first come, que atribui a titularidade de domínio a quem primeiro requerer o seu registro junto ao órgão competente.

\subsection{CONFLITOS JURISDICIONADOS? CASOS SUBMETIDOS À ICANN E AO CGI.BR}

Evidenciado o conflito existente entre nomes de domínio, é preciso esclarecer como se dá a resolução prática deste. Observe que, em se tratando de internet, tudo é muito rápido. Assim, eventual conflito deve ser solucionado com a rapidez que a rede mundial de computadores demanda.

Neste norte, um domínio secundário, registrado junto ao CGI.br, será submetido a um sistema de resolução de conflitos deste órgão. Isso conforme o artigo $1^{\circ}$ do regulamento do sistema administrativo de conflitos de internet relativos a nomes de domínios sob "BR" - denominado SACI-Adm. Ademais, o CGI.br credencia órgãos para a resolução dos conflitos. Atualmente são credenciadas a Associação Brasileira da Propriedade Intelectual, Câmara de Comércio Brasil-Canadá e a WIPO.

Tratando-se de um domínio top level, utilizando apenas a designação ".com”, o qual é registrado junto a ICANN, nela deverá solucionar seu conflito, também da forma administrativa. A peculiaridade é que a ICANN adotou um sistema unificado para a solução de conflitos, o qual se processa na WIPO, que atualmente conta com um Serviço de Solução de Disputas Relativas a Nomes de Domínio ${ }^{29}$.

Portanto, todo e qualquer domínio de primeiro nível, caso tenha um conflito, poderá ser solucionado na WIPO. O mesmo acontece com os domínios registrados no CGI.br, o que evidencia o sistema de resolução de conflitos que foi criado em 1999. Conforme Geist ${ }^{30}$, o referido mecanismo é nomeado de Uniform Dispute Resolution Policy (UDRP). O procedimento se assemelha a arbitragem ${ }^{31}$ e é feito totalmente online.

Seu contexto de criação veio com a difusão do Cybersquatting e Typosquatting. O Cybersquatting nada mais é que o registro de uma marca de

\footnotetext{
${ }^{29}$ Disponível em <http://www.wipo.int/amc/pt/domains/gtld/udrp/\#1>

${ }^{30}$ GEIST, Michael. Fair.com?: Uma investigação sobre alegações de deslealdade sistêmica na ICANN UDRP. In: LEMOS, Ronaldo. WAISBERG, Ivo. Conflitos Sobre Nomes de Domínio e Outras Questões Jurídicas da Internet, São Paulo: Revista dos Tribunais, 2003. p. 133/178

${ }^{31}$ Não se trata de arbitragem pois as partes do procedimento não anuíram a clausula ou compromisso arbitral. Há um contrato entre o usuário que registrou o domínio e o órgão (CGI.br ou Icann, por exemplo), no qual se estipula a submissão de casos ao referido sistema, mas o que não caracteriza arbitragem, pois o terceiro não anuiu à referida cláusula. Entretanto, o sistema é similar à arbitragem.
} 
outrem como nome de domínio, dada a confusão existente entre estes institutos. Por sua vez, o Typosquatting é o registro de nomes de domínio com pequenos erros de grafia como, por exemplo, "www.exmplo.com.br", note que a omissão da letra "e", se lido sem cautela, não é tão clara ${ }^{32}$.

Atualmente, podem ser submetidos à análise do órgão casos que envolvam nome de domínio idêntico ou similar à marca entre outros. Assim, caso um empresário sinta-se prejudicado pelo uso de domínio que conflite com marca registrada, poderá submeter o caso a análise da WIPO. Para decidir o caso, a comissão designada avaliará quatro fatores que evidenciam a má fé, são eles:

1 - circunstâncias que indicam que o objetivo principal é vender ou transferir o nome do proprietário da marca registrada ou concorrente para apreciação em excesso de custos relacionados com o nome de domínio; ou

2 - história do registro, a fim de impedir o titular do IP de refletir a sua marca em um nome de domínio; ou

3 - registro principalmente para o propósito de prejudicar a atividade comercial de um concorrente; ou

4 - tentativas intencionais para atrair usuários para seu site para fins comerciais, criando um risco de confusão quanto à origem ou endosso. (tradução nossa) $)^{33}$

Portanto, havendo intuito de venda do domínio fica caracterizada a má-fé do titular deste. A história do registro também é relevante na análise do caso. Por fim, afirma-se que o sistema unificado de resolução de conflitos se refere apenas aos nomes de domínios e a decisão se limita a transferência ou cancelamento deste ${ }^{34}$. Não há, pois, possibilidade de se cancelar um registro de marca.

É claro que, querendo, pode-se instaurar um processo judicial, até mesmo por que o inciso XXXV do artigo $5^{\circ}$ da $\mathrm{CR} / 88$ normatiza que "a lei não excluirá da

32 MENDES, Carolina de Aguiar Teixeira. Proteção digital da marca: Cybersquatting e Typosquatting. Âmbito Jurídico, Rio Grande, X, n. 39, mar 2007. Disponível em: < http://www.ambito-juridico.com.br/site/index. php?n_link=revista_artigos_leitura\&artigo_id=3730>. Acesso em 05 de maio 2015.

331 - circumstances indicating that the primary purpose is to sell or transfer the name to the trademark owner or competitor for consideration in excess of direct costs related to the domain name; or

2 - history of registration in order to prevent the IP owner from reflecting their mark in a domain name; or

3 - registration primarily for the purpose of disrupting the business of a competitor; or

4 - intentional attempts to attract users to your site for commercial gain, by creating a likelihood of confusion as to source or endorsement. (HARVARD, 2015)

${ }^{34}$ HARVARD. Uniform Dispute Resolution Policy. Disponível em: < http://cyber.law.harvard.edu/property00/ domain/udrp.html > . Acesso em: 05 maio 2015. 
apreciação do Poder Judiciário lesão ou ameaça a direito"35. Destarte, o procedimento judicial é lento, o que trará uma decisão de certo inefetiva ${ }^{36}$, visto que a internet demanda celeridade.

\subsection{FIRST SERVED, FIRST COME OU PRIORIZAÇÃO DO DIREITO MARCÁRIO?}

Percebe-se uma tendência em se privilegiar a marca, o que deve ser relativizado. Nesta linha de raciocínio, estão Dornaus ${ }^{37}$ e Brugioni ${ }^{38}$. Como visto, a própria WIPO, em seu UDRP coloca como má-fé o registro de domínio que utiliza marca alheia. Mas como afirma Kaminski ${ }^{39}$, "a marca não pode ser um critério isolado, no caso de ser comparada com um nome de domínio".

É claro que no registro das marcas há uma análise rigorosa do mérito. No INPI, um pedido de registro passa por duas análises, uma formal e outra material, sendo que de ofício há uma busca para que se evite o registro de marcas conflitantes. Entretanto, o fato de não haver uma análise de mérito dos nomes de domínio não significa que a marca deverá ser sempre privilegiada. Deve-se repensar a atual forma de resolução de conflitos, na qual a maioria dos casos submetidos à análise do judiciário ou da UDRP são vencidos por aquele que litiga embasado na titularidade de marca, conforme é exposto por Geist ${ }^{40}$ e Kaminski ${ }^{41}$.

Tal fato leva a uma prática denominada Cybersquatting reversa ${ }^{42}$. Nesta, o empresário, buscando que lhe seja confiado o uso de domínio já registrado e não

\footnotetext{
35 BRASIL. Constituição da República Federativa do Brasil dE 1988.

${ }^{36}$ A jurisdição será eficaz quando conseguir atingir o seu objetivo que é a proteção de um direito ou de uma situação jurídica pela via jurisdicional. Já a análise da efetividade não é apenas quanto ao resultado da jurisdição, é preciso se averiguar como foi construída a relação processual, é preciso se analisar a moldura em que está inserido o processo.

37 DORNAUS, Victor Pellegrino da Silva. Conflitos entre marca registrada, nome empresarial e nome de domínio. Revista Jus Navigandi, Teresina, ano 19, n. 4128, 20 out. 2014. Disponível em: < http://jus.com.br/ artigos/30404>. Acesso em: 24 maio 2015

${ }^{38}$ BRUGIONI, Franco Mauro Russo. Conflitos entre marca e nome de domínio na internet. Revista Jus Navigandi, Teresina, ano 19, n. 4184, 15 dez. 2014. Disponível em: < http://jus.com.br/artigos/31355> . Acesso em: 24 maio 2015

${ }^{39}$ KAMINSKI, Omar. Conflitos sobre nomes de domínio: a experiência com o Judiciário brasileiro. In: LEMOS, Ronaldo. WAISBERG, Ivo. Conflitos Sobre Nomes de Domínio e Outras Questões Jurídicas da Internet. São Paulo: Revista dos Tribunais, 2003. p. 252

${ }^{40}$ GEIST, Michael. Fair.com?: Uma investigação sobre alegações de deslealdade sistêmica na ICANN UDRP. In: LEMOS, Ronaldo. WAISBERG, Ivo. Conflitos Sobre Nomes de Domínio e Outras Questões Jurídicas da Internet, São Paulo: Revista dos Tribunais, 2003. p. 133/178

${ }^{41}$ KAMINSKI, Omar. Conflitos sobre nomes de domínio: a experiência com o Judiciário brasileiro. In: LEMOS, Ronaldo. WAISBERG, Ivo. Conflitos Sobre Nomes de Domínio e Outras Questões Jurídicas da Internet, São Paulo: Revista dos Tribunais, 2003. p. 242/271

${ }^{42}$ SINGH, Snehlata. Conflicts between Trademarks and Domain Names: A Critical Analysis. Disponível em: $<$ http://ssrn.com/abstract $=2045222>$. Acesso em 05 de maio de 2015
} 
tendo o registro de marca pretérito, requer o registro desta posteriormente. Este fato evidencia o quão prejudicial pode ser um sistema de resolução de conflitos que presume como má-fé o uso de um domínio registrado como marca por outrem.

Não se afirma que o princípio da primeira posse dos nomes de domínio deve sempre prevalecer. Evidente que em alguns casos a má-fé do titular é evidente. Porém, o fato de se ter uma marca registrada não caracteriza, ou não devia caracterizar, por si só, a má-fé.

Sobre a UDRP da WIPO, Michael Geist ${ }^{43}$ fez uma análise sistêmica sobre os casos submetidos à resolução até o ano de 2001. Em seu trabalho, constatou que em $82,2 \%$ dos casos houve êxito do reclamante, o que faz pensar a política de resolução.

Ora, como 82,2\% dos casos determinaram a transferência ou cancelamento de domínio, aplica-se ao nome de domínio realmente o princípio do first served, first come? É preciso que se análise com cautela tal instituto. Deferir a posse de domínio para depois se retirar pode não ser uma medida inteligente. Isso porque para o desenvolvimento de um website há investimento, o qual pode ser perdido por uma decisão posterior. O que se quer afirmar é que seria mais eficaz o controle no momento do requerimento do registro, realizando não só uma análise formal, mas também uma análise de mérito.

Neste sentido, o registro de domínio deveria seguir alguns princípios mais hígidos. Assim, com um controle preventivo, a ocorrência dos conflitos aqui evidenciados pode ser reduzida, sem que isso caracterize ofensa aos princípios da livre concorrência e da livre iniciativa. Isto é, a análise de mérito iria evitar práticas de cybersquatting e typosquatting.

\section{CONCLUSÃO}

Como visto, a internet tem reflexos na atividade empresária. Pode-se afirmar que o empresário a utiliza para exercer a empresa. Dessa forma, os nomes de domínio são de suma importância, tendo em vista que identificam a atividade na rede mundial de computadores. Por sua vez, as marcas também possuem grande relevância. Estas identificam produtos e serviços, os quais também podem ser

\footnotetext{
43 GEIST, Michael. Fair.com?: Uma investigação sobre alegações de deslealdade sistêmica na ICANN UDRP. In: LEMOS, Ronaldo. WAISBERG, Ivo. Conflitos Sobre Nomes de Domínio e Outras Questões Jurídicas da Internet. São Paulo: Revista dos Tribunais, 2003. p. 133/178
} 
inseridos em meio digital.

Entretanto, os princípios norteadores dos domínios e das marcas são distintos, bem como os órgãos registradores. Assim sendo, surge a possibilidade de conflitos entre marcas e domínios, sendo que como visto, há uma tendência dos órgãos julgadores em privilegiar a marca, o que deve ser relativizado.

O nome de domínio deve ser visto com a cautela e importância que lhe é devida. Não se quer afirmar que este deve sempre preponderar sobre as marcas. Entretanto, a análise deve ser feita caso a caso, pois só assim se saberá qual decisão deve ser tomada.

Neste contexto, a investigação mostrou que a má-fé é um elemento que ajuda a identificar qual dos institutos deve prevalecer. Entretanto, atualmente se considera de má-fé aquele que utiliza como domínio marca de outrem, o que não deve prevalecer, tendo em vista ser essa um elemento subjetivo e deve ser verificada caso a caso.

A prática hoje mostra que aquele que pretende utilizar um domínio tem de registrar também a marca, o que é tido como uma exigência implícita. Isso ocorre em virtude do fato de que o titular da marca tem tido preferências nos conflitos com nomes de domínio, sendo essa inclusive a primeira orientação da WIPO em seu sistema de resolução de conflitos.

Neste sentido, os conflitos entre marcas e nomes de domínio continuarão a existir enquanto o sistema de nomes de domínio for do jeito que é. É claro que o processo de abstração das normas e sistemas é lento. Isso se deve ao fato de que, como a internet é um fenômeno relativamente recente, é possível que em um futuro próximo se tenham normas, aqui entendidas em latu sensu (leis, costumes, jurisprudência, princípios etc), que consigam regulamentar e prevenir conflitos como os que aqui foram expostos.

\section{REFERÊNCIAS}

BARBOSA, Denis Borges. Uma Introdução à Propriedade Intelectual. 2. ed. Rio de Janeiro: Lumen Iuris, 2003

BARROS, Carla Eugenia. Manual da Propriedade Intelectual. Aracaju: Evocati, 2007. 
BRANT, Cássio Augusto Barros. Marco Civil da Internet: comentários sobre a Lei 12.965/2014. Belo Horizonte: D’Plácido, 2014.

BRANT, Cássio Augusto Barros. Usucapião do direito de uso da propriedade intelectual. Disponível em: < http://www.biblioteca.pucminas.br/teses/Direito BrantCA_1.pdf $>$. Acesso em: 05 maio 2015.

BRASIL. Constituição da República Federativa do Brasil de 1988.

BRUGIONI, Franco Mauro Russo. Conflitos entre marca e nome de domínio na internet. Revista Jus Navigandi, Teresina, ano 19, n. 4184, 15 dez. 2014. Disponível em: < http://jus.com.br/artigos/31355> Acesso em: 24 maio 2015.

CGI.BR - Comitê Gestor da Internet no Brasil. Resolução CGI.br/ RES/2008/008/P. Dispõe sobre os procedimentos para registro de nomes de domínio. Disponível em: < http://www.cgi.br/resolucoes/documento/2008/008>. Acesso em: 17 set. 2014.

CGI.BR - Comitê Gestor da Internet no Brasil. Regulamento do Sistema Administrativo de Conflitos de Internet Relativos a Nomes de Domínios sob “.BR" - Denominado SACI-Adm. Disponível em: < http://registro.br/dominio/saciadm-regulamento.html>. Acesso em: 17 set. 2015.

COELHO, Fábio Ulhoa. Manual de Direito Comercial: direito de empresa. 23. ed. São Paulo: Saraiva, 2011.

CORRÊA, Júlio César Dutra. Nome de domínio: Enseja proteção equiparável às marcas ou é apenas mais um signo distintivo para o exercício da atividade empresarial?. Âmbito Jurídico, Rio Grande, XV, n. 96, jan. 2012. Disponível em: $<$ http://www.ambito-juridico.com.br/site/?n_link=revista_artigos_leitura\&artigo_ $\mathrm{id}=11054 \&$ revista_caderno $=8>$. Acesso em: set 2014 .

CORTE ALEMÃ julga internet como serviço essencial. Mundo Positivo. 25 jan. 2013. Disponível em: < http://www.mundopositivo.com.br/noticias/ brasil/20138626-corte_alema_julga_internet_como_servico_essencial.html > Acesso em: 25 jan. 2015.

DORNAUS, Victor Pellegrino da Silva. Conflitos entre marca registrada, nome empresarial e nome de domínio. Revista Jus Navigandi, Teresina, ano 19, n. 4128, 20 out. 2014. Disponível em: < http://jus.com.br/artigos/30404> Acesso em: 24 maio 2015.

GEIST, Michael. Fair.com?: Uma investigação sobre alegações de deslealdade 
sistêmica na ICANN UDRP. In: LEMOS, Ronaldo. WAISBERG, Ivo. Conflitos Sobre Nomes de Domínio e Outras Questões Jurídicas da Internet. São Paulo: Revista dos Tribunais, 2003. p. 133/178.

GUIMARÃES, Ana Caroline Faria; NEVES, Rubia Carneiro. El Establecimiento Virtual Y Su Condición De Establecimiento Empresarial Secundario (FILIAL). Panorama of Brazilian Law, v. 2, n. 2, 2014. Disponível em < http://www. panoramaofbrazilianlaw.com/index.php/BrLaw/article/view/30>. Acesso em: 04 maio 2015.

HARVARD. Uniform Dispute Resolution Policy. Disponível em: < http://cyber. law.harvard.edu/property00/domain/udrp.html > . Acesso em: 05 maio 2015.

KAMINSKI, Omar. Conflitos sobre nomes de domínio: a experiência com o Judiciário brasileiro. In: LEMOS, Ronaldo. WAISBERG, Ivo. Conflitos Sobre Nomes de Domínio e Outras Questões Jurídicas da Internet. São Paulo: Revista dos Tribunais, 2003. p. 242/271.

MENDES, Carolina de Aguiar Teixeira. Proteção digital da marca: Cybersquatting e Typosquatting. Âmbito Jurídico, Rio Grande, X, n. 39, mar. 2007. Disponível em: < http://www.ambito-juridico.com.br/site/index.php?n_link=revista_artigos leitura\&artigo_id $=3730>$. Acesso em: 05 maio 2015.

SINGH, Snehlata, Conflicts between Trademarks and Domain Names: A Critical Analysis. Disponível em: < http://ssrn.com/abstract=2045222>. Acesso em: 05 maio 2015. 